\title{
Geophysical Investigation of the Site of the Former Monastic Settlement, Clonard, County Meath, Ireland
}

\author{
PAUL J. GIBSON* AND DOROTHY M. GEORGE
}

Environmental Geophysics Unit, Department of Geography, National University of Ireland, Maynooth, Co. Kildare, Republic of Ireland

\begin{abstract}
Clonard, in County Meath, Ireland was a major ecclesiastical centre from the early sixth century to the twelfth century and buildings associated with the monastery were in existence until the late eighteenth century. However, today no extant buildings or features associated with the monastery are known. The geophysical investigation undertaken in this project has uncovered many anomalies which may be related to the monastic settlement at Clonard. A significant number of linear anomalies have been detected east of St Finian's church using magnetic gradiometry and twin electrode resistance surveying. Many of these anomalies are probably field boundaries; however, a much greater diversity of geophysical responses is located south and west of St Finian's church. A subsquare enclosure of $60 \mathrm{~m}$ sides is adjacent to a $300 \mathrm{~m}$ long palaeochannel. A fine network of intersecting low resistance anomalies probably represent former artificial drainage channels. Three large areas associated with anomalous magnetic readings were located which might indicate sites of human activity. In addition, there are four distinct zones which have large concentrations of high resistance values suggesting the presence of walls or buildings. Resistivity and ground-penetrating radar depth slices show that one of these zones has characteristics which indicate the presence of an east-west aligned building approximately $7 \mathrm{~m}$ wide in a north-south direction and about $15 \mathrm{~m}$ long in an east-west direction. Copyright (c) 2005 John Wiley \& Sons, Ltd.
\end{abstract}

Key words: Clonard; Ireland; monastic settlement; resistivity and ground-penetrating radar depth slices; pseudosection

\section{Introduction}

Clonard, today is a small village in County Meath $62 \mathrm{~km}$ west of Dublin, Ireland (Figure 1 inset). However, for a period of at least 700 years it was one of the most important and influential ecclesiastical centres in Ireland. A monastery was founded at Clonard in the early sixth century by St Finian (Finnian), who is known as the Master of the Saints of Ireland due to the large number of

* Correspondence to: P. J. Gibson, Environmental Geophysics Unit, Department of Geography, National University of Ireland, Maynooth, Co. Kildare, Republic of Ireland.

E-mail: Paul.Gibson@nuim.ie important bishops who studied under him at Clonard, for example, Ciaran of Clonmacnoise, Colmcille of Iona, Molaise of Devenish and Brendan of Clonfert (D'Arcy, 1974; Flanagan, 1990). Archaeological finds in the area, such as a ninth century shrine and eleventh century crozier, also attest to the ecclesiastical importance of this site. The annals of Clonard record the major events in Clonard's history.

It was plundered in the year AD 887 by the Vikings and in the year 970 by Domhnall MacMurchadh. Vikings also raided Clonard, along with other important monastic sites in AD 1012 and again in AD 1020 and in AD 1045 its great stone church was destroyed in such an attack 


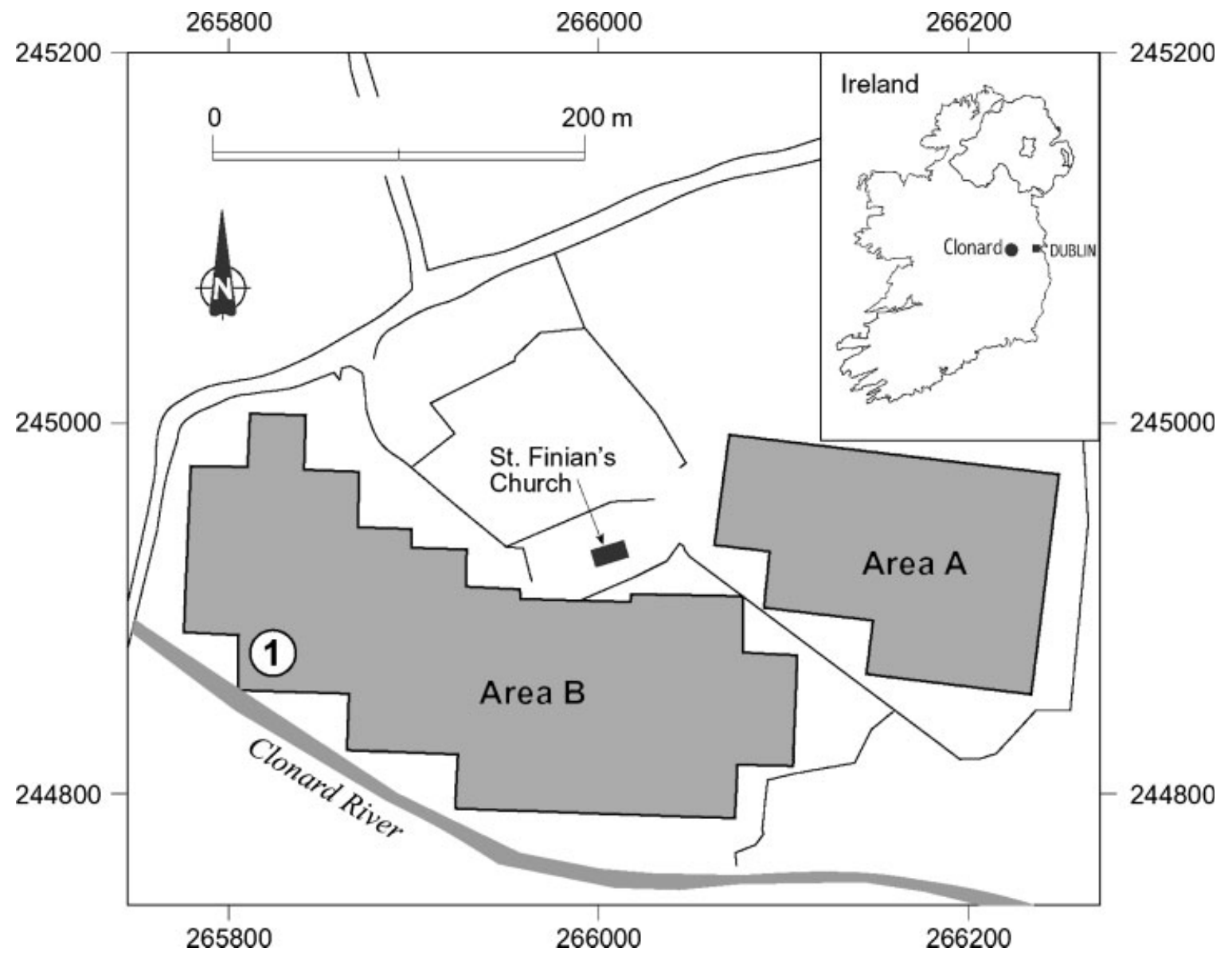

Figure 1. Location map of study area, Clonard, County Meath, Ireland. Areas A and B were investigated using magnetic gradiometry and resistance techniques. In addition, ground-penetrating radar and resistivity data were collected at locality 1 . National Irish grid co-ordinates.

(Cogan, 1874). The bishopric of Clonard maintained its ecclesiastical importance into the twelfth century when it became the diocesan town of East Meath (Hickey, 1998). However, the importance of Clonard then decreased and was dissolved by Henry VIII around 1542 in the Dissolution of the Monasteries. Up to the end of the eighteenth century, there are records of substantial parts of the monastery and its associated buildings remaining. Archdall (1786) reports the existence of buildings and that the choir was 'a large and elegant building, most of which remains'. However, nothing exists today and in the first edition 6 inch to 1 mile Ordnance Survey map of the Clonard area, published in 1836, not a single feature is shown, although it is recorded that the 'site of abbey' is located where the present day St Finian's church is shown (Figure 1).

A geophysical study was undertaken during the summer of 2004 in two areas (areas A and B, Figure 1) in the vicinity of St Finian's church in order to determine if any anomalies associated with Clonard monastery could be detected. The geology in this region consists of non-magnetic Carboniferous Limestone overlain by glacial sediments and soil. There is no published information on the thickness of the superficial cover but it is believed to be at least $3 \mathrm{~m}$ thick. Aerial photography shows a number of linear features in area B which were shown by Sweetman (1978) to be late thirteenth century drainage channels. 
They are not related to the present-day Clonard river (a relatively recent canalized feature) which forms the southern boundary of Area B.

\section{Data collection, techniques and processing}

Data were collected at two locations: east (area A) and south and west (area B) of the present-day St Finian's church (Figure 1). Magnetic and resistance data were collected in $30 \times 30 \mathrm{~m}$ grids, 20 grids in area A and 42 in area $\mathrm{B}$.

The resistance survey was undertaken using a TRCIA twin electrode array with a $0.5 \mathrm{~m}$ electrode spacing. The data were collected in a zigzag fashion at $1 \mathrm{~m}$ intervals along $1 \mathrm{~m}$ spaced parallel lines. Nine hundred data points were collected for a $30 \times 30 \mathrm{~m}$ grid resulting in 18000 resistance readings for area $\mathrm{A}$ and 37800 readings for area B. The data were combined into a mosaic using Geoscan Research's Geoplot software and where necessary the grids were matched. The processed data were output and gridded in Golden Software's Surfer program. A boundary file was used in order to 'cookie-cut' the resultant images so that they matched the area over which data were collected. The images were georeferenced to Irish grid co-ordinates using GPS technology and input into the ArcMap Geographical Information System.

Magnetic data were collected along the same survey lines as those used in the resistance survey using a Bartington 601 gradiometer. Data were collected in a zig-zag pattern at a walking speed of $1.1 \mathrm{~m} \mathrm{~s}^{-1}$ along $1 \mathrm{~m}$ spaced lines with a station spacing of $0.25 \mathrm{~m}$ for each line. Thus 3600 reading were acquired for each $30 \times 30 \mathrm{~m}$ grid (72000 readings for area $\mathrm{A}$ and 151200 readings for area B). A similar processing stream was used for the magnetic data as for the resistance data. However, in addition, the data were despiked in order to remove spurious high or low readings and a zero mean grid algorithm used.

Electrical imaging and ground-penetrating radar (GPR) surveys were conducted at one location in area B (1, Figure 1). Ten parallel lines of resistivity data were collected in a south-north direction along $19.2 \mathrm{~m}$ long lines spaced $1.5 \mathrm{~m}$ apart. A Campus Geopulse resistivity meter with 25 electrodes spaced $0.8 \mathrm{~m}$ apart was used in this investigation. The Wenner-Schlumberger electrode array was used as it gives a good signal strength and is reasonably good at detecting both lateral and vertical resistivity changes (Loke, 2001; Similox-Tohon et al., 2004). Twodimensional electrical imaging allows the acquisition of apparent resistivity variations in both the vertical and horizontal directions, effectively producing a two-dimensional slice known as a pseudosection. Although this pseudosection provides some information about the subsurface, different results would be produced for the same profile if different electrode arrays were used. The data were subsequently modelled using the RES2DINV inversion program (produced by Geotomo Software) in order to determine how the 'true' resistivity may vary with depth. The subsurface is divided into a number of rectangles which are assigned true resistivity values and an initial model of the subsurface formed which shows the variation in 'true' resistivity with modelled depth. The apparent resistivity that this model would yield for the selected electrode array that is used is then calculated and compared with the measured apparent resistivity. The model is then progressively altered using a least-squares optimization approach in order to reduce the root mean square (RMS) error between the calculated and measured apparent resistivity (Loke and Barker, 1995, 1996). The number of iterations can be specified or the process can be stopped once the change between two iterations is below a specified threshold value. The ten individual parallel lines which together comprised a rectangle $19.2 \mathrm{~m}$ long in a north-south direction (25 electrodes with a spacing of $0.8 \mathrm{~m}$ ) and $13 \mathrm{~m}$ wide in an east-west direction (each line $1.5 \mathrm{~m}$ from the adjacent ones) were modelled using the RES3DINV inversion program. This allowed the production of areal resistivity maps for different depths (see Figure 7).

A Sensors \& Software pulseEKKO 100 system operating in constant separation mode at a central frequency of $200 \mathrm{MHz}$ was used to collect ground-penetrating radar data in the same vicinity as the resistivity data. Twenty-one $13 \mathrm{~m}$ long parallel ground-penetrating radar (GPR) lines of 
data were collected in a south-north direction. Data were collected at $10 \mathrm{~cm}$ intervals along each line and each line was separated by $50 \mathrm{~cm}$ from adjacent ones. All GPR data were 'dewowed' before being examined. This is because the low frequency component of the transmitted radar pulse slowly decays and the reflections are superimposed on this decaying transient (Sensors \& Software Inc., 1996). Consequently, GPR data are high-pass filtered (dewowed) to pass the antenna centre frequency and to suppress the low frequency component. All data were also 'gained' in order to compensate for the considerable decrease in energy as the waves travel deeper, which produces weak signals from deeper sources. An automatic gain control (AGC) was applied which is inversely proportional to the decaying signal strength; thus a greater gain was applied to deeper reflectors. A time window of $100 \mathrm{~ns}$ was used and 16-fold stacking used to improve the signal-to-noise ratio. A subsurface velocity of $0.08 \mathrm{~m} \mathrm{~ns}^{-1}$ was used in all depth calculations. This value was obtained using a hyperbola matching technique (Gibson and George, 2004). The 21 closely spaced parallel lines of ground-penetrating radar data were merged using the Sensors \& Software EkkoMapper computer program to produce a sequence of two-dimensional plots showing the spatial variation in amplitude for different depth slices (see Figure 9). The deviation from the norm is important and no differentiation is made between positive or negative amplitudes (Conyers and Goodman, 1997).

\section{Results of magnetic investigation}

The results of the magnetic investigation are shown in Figure 2. Examination of the magnetic data for area A shows there is a distinct difference between the western and eastern halves of the region. There are virtually no magnetic anomalies east of Irish Grid easting 266150 (1, Figure 2), whereas to the west the magnetic data are much more variable and a significant number of linear anomalies can be observed. This boundary is marked by a concentration of approximately $\mathrm{N}-\mathrm{S}$ trending linear features. This change may have a geological origin but the

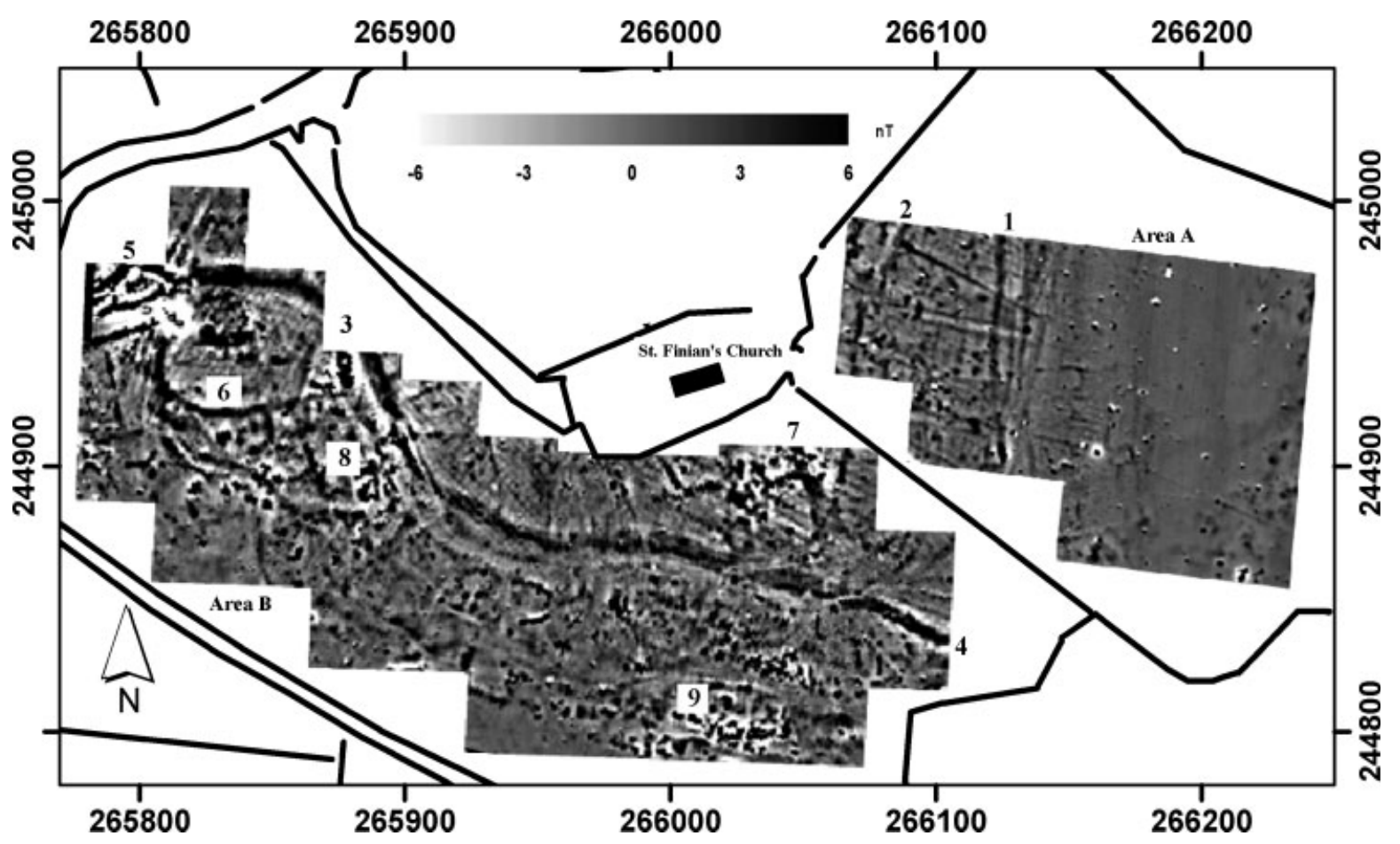

Figure 2. Magnetic data for areas A and B. 
distinction does not appear on the resistance data (see Figure 3). An arcuate anomaly can be seen on the western side of area A (2, Figure 2).

The magnetic data for Area B are dominated by the $300 \mathrm{~m}$ long undulating structure that crosses the entire image (3-4, Figure 2). This anomaly is approximately $6 \mathrm{~m}$ wide and has a positive (dark) magnetic signature in the core being flanked by a negative (paler) signature. This feature does not have an archaeological origin but represents an old unknown river channel which may have become silted up during the drainage of this area in the thirteenth century. The infilled channel is more magnetic than its adjacent banks because of the thicker sediment cover. The westward continuation of this channel could not be determined due to the presence of high voltage wires and pylons (5, Figure 2).

A very prominent $70 \mathrm{~m}$ arc can be observed in the western section of area B, which also may be a former channel (6, Figure 2). There are two areas in this field where there are zones of fine parallel lines extending for $60-70 \mathrm{~m}$. These lines most likely represent old plough marks. They have different trends and are most prevalent in the northern section of area B. They have a NESW (6, Figure 2) and a WNW-ESE trend (7, Figure 2). The latter pattern extends northwards into area $\mathrm{B}$.

In any large field there is often a random scatter of small isolated high and low magnetic anomalies caused by, for example, nails, slag, etc. However, any concentrations of such material tend to suggest general anthropogenic activity and possibly the location of settlement (Gaffney and Gater, 2003). Such concentrations, extending up to $50 \mathrm{~m}$, are located at positions 7, 8 and 9, Figure 2. Location 7 is adjacent to the supposed site of the abbey and location 8 is beside the former river channel.

\section{Results of resistance investigation}

Area $\mathrm{A}$ is characterized by a number of major low resistance linear anomalies with different trends (Figure 3). The longest one (1, Figure 3) can be observed extending across this area for about $150 \mathrm{~m}$. It also corresponds with a former

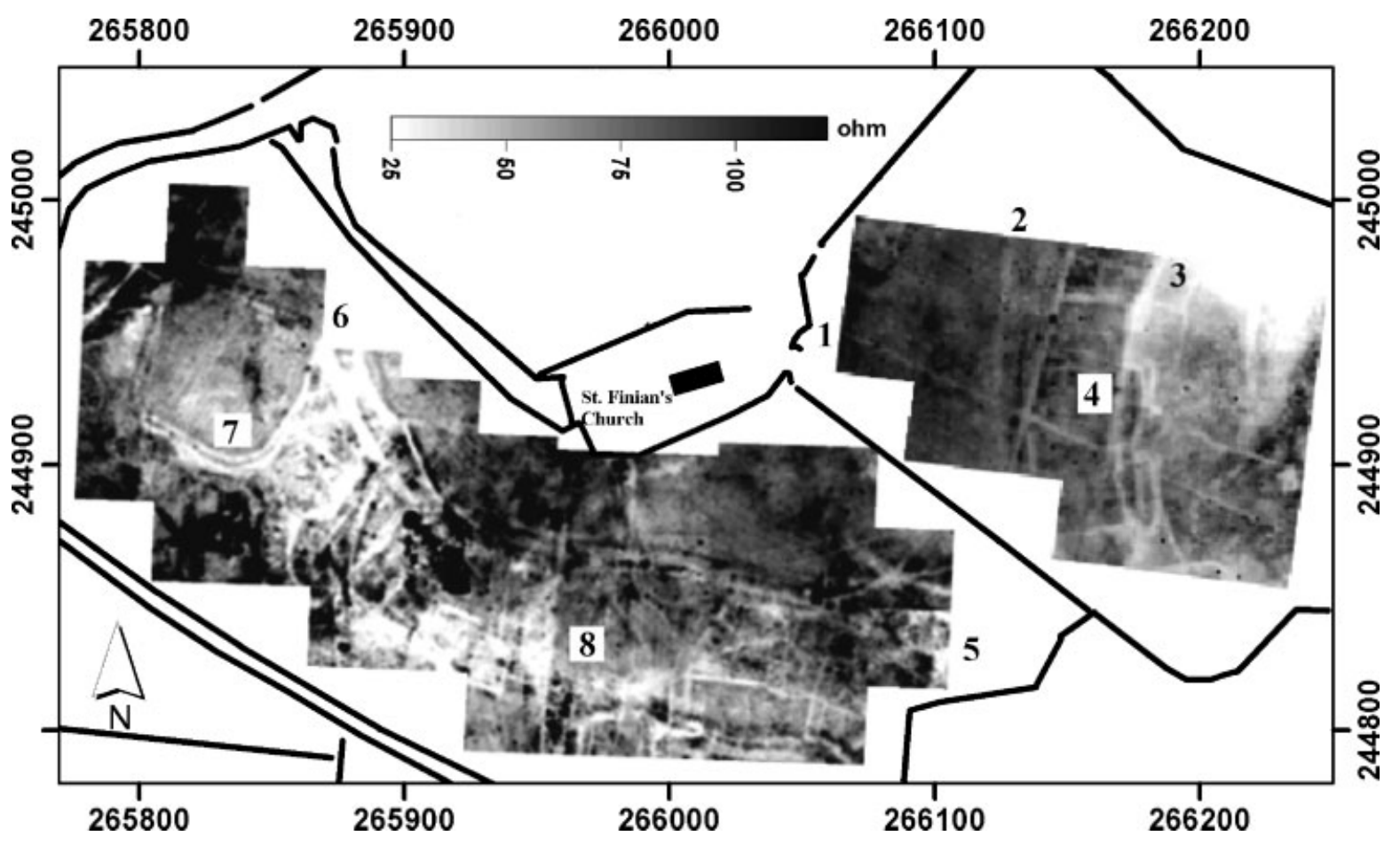

Figure 3. Resistance data for areas A and B. 
field boundary shown on the 19106 inch to 1 mile Ordnance Survey map of the area. A concentration of $\mathrm{N}-\mathrm{S}$ trending resistance features is located in a similar position to magnetic lineaments (2, Figure 3). Whereas the eastern half of area $\mathrm{A}$ is magnetically quiet, a number of low resistance linear features can be observed in this region which probably represent former field boundaries (3 and 4, Figure 3). There is a noticeable decrease in resistance east of the arcuate boundary (3, Figure 3).

The river channel observed in the magnetic data for area B (Figure 2) can still be discerned on the resistance data, although the trend is not as clearly defined (5-6, Figure 3 ). A subsquare enclosure with dimensions approximately $60 \times 60 \mathrm{~m}$ is located in the western part of area B (7, Figure 3). A distinctive ploughing pattern similar to that seen on the magnetics is evident at this location. The region south of the palaeochannel is characterized by a network of short intersecting linear anomalies (8, Figure 3). They are absent north of the palaeochannel and most likely represent late thirteenth century drainage channels known to exist in this region (Sweetman, 1978).

Archdall (1786) recorded the presence of stone walls and buildings and such features are generally associated with high resistances (Gaffney and Gater, 2003; Gibson and George, 2004). A modified version of Figure 3 is displayed in Figure 4 in which low and medium resistance values are saturated to white and only the highest values represented by black. It is clear that the high resistance areas are not randomly scattered throughout area B but concentrated in small compact zones which suggest that these areas may represent the locations of walls or buildings. Four such zones are shown in Figure 4. The Irish grid co-ordinates for the centre of zone 1 are 265826 E $244874 \mathrm{~N}$; for zone 2 are $265816 \mathrm{E}$ $244978 \mathrm{~N}$; for zone 3 are $265918 \mathrm{E} 244862 \mathrm{~N}$; for zone 4 are $265963 \mathrm{E} 244906 \mathrm{~N}$. A directionally filtered version of zone 1 is displayed in Figure $5 \mathrm{a}$ and interpreted in Figure 5b. This area is topographical higher than areas around it and parts of stones could be determined above the soil. Background resistance is of the order of

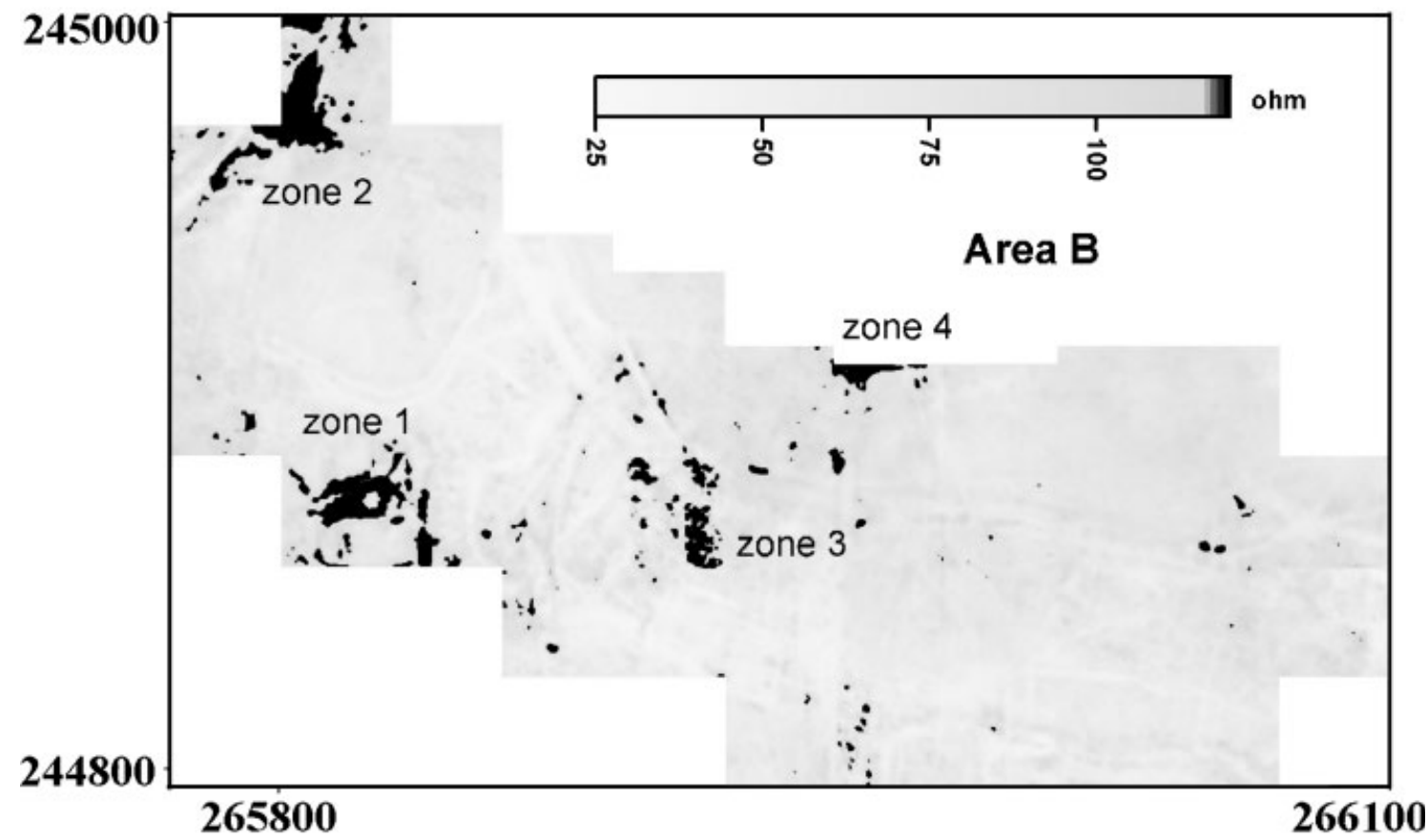

Figure 4. Resistance data for area B modified to show location of high resistance concentrations. Zone 1 was further investigated using ground-penetrating radar and resistivity. 

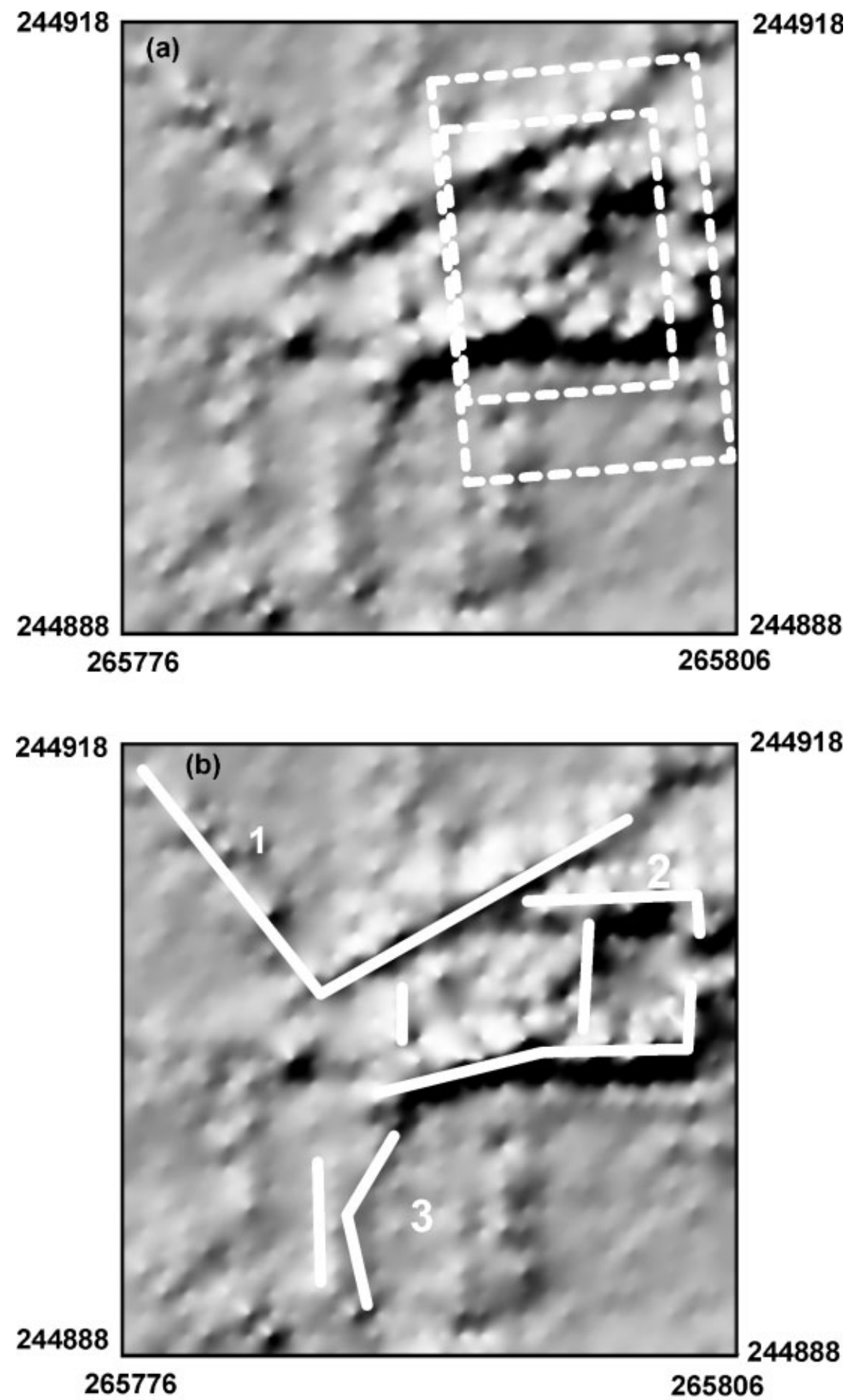

Figure 5. (a) Filtered resistance data and (b) interpretation. Numbers referred to in text. Large rectangle in (a) shows area covered by two-dimensional resistivity plots (see Figure 7) and the small rectangle in (a) shows area covered by ground-penetrating radar plots (see Figure 9). 
80 ohms whereas the linear anomalies that can be observed have resistances of up to $300 \mathrm{ohms}$. Two anomalies which meet approximately at right angles may represent former field boundaries (1, Figure 5b). These appear to cut across another feature (2, Figure $5 \mathrm{~b})$ which due to its shape and resistance signature is interpreted as a building. This building has its long axis oriented $\mathrm{E}-\mathrm{W}$ and an opening can be determined on the east wall. It is approximately $7 \mathrm{~m}$ wide (N-S direction) and about $15 \mathrm{~m}$ long $(\mathrm{E}-\mathrm{W})$. An internal division can be distinguished with the western half of the building being associated with a higher resistance than the eastern part. The eastern part may simply be an earthen floor whereas the western part of the building may have a stone floor. The building was further investigated using ground-penetrating radar and resistivity.

\section{Resistivity characteristics of zone 1}

A series of parallel south-north resistivity lines was obtained across the building in zone 1, all of which showed the same consistent pattern. The modelled results of three of these traverses using RES2DINV inversion program are shown in Figure 6. Resistivity values are generally low (50-150 ohm m) except where the traverses cut across the east-west aligned walls. These are located at $6.4 \mathrm{~m}$ and $13.6 \mathrm{~m}$ and are represented by very high resistivity values in the range 1000$3000 \mathrm{ohm} \mathrm{m}$, an order of magnitude greater than the background readings. These high values are consistent with stone walls. It is difficult to accurately define the dimensions of the walls. However, the data suggest that they are of the order of $50-80 \mathrm{~cm}$ in thickness and extend to a
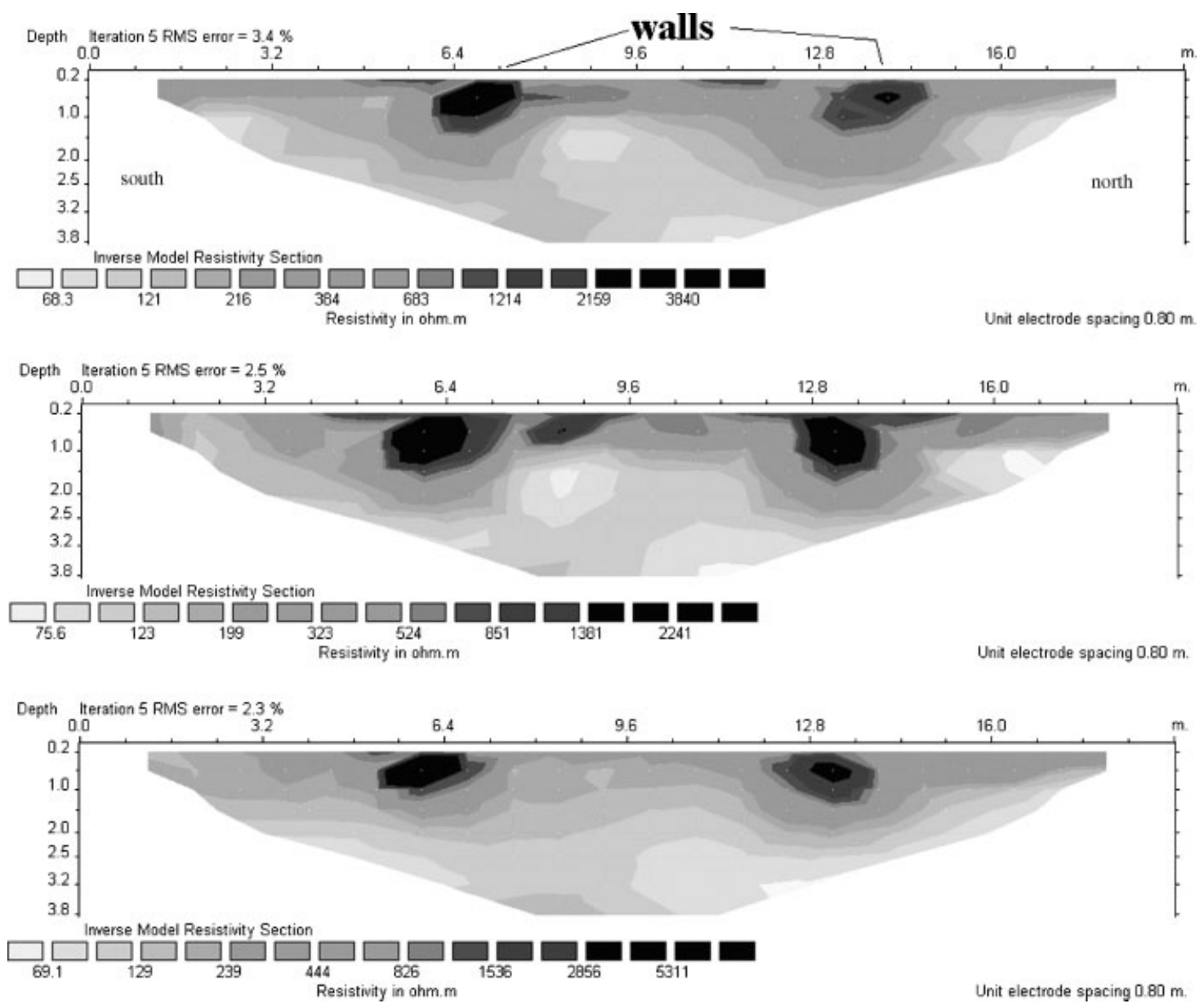

Figure 6. Three lines of two-dimensional resistivity models across zone 1 showing the location of high resistivity walls. 
depth of about $1 \mathrm{~m}$ below the surface, suggesting that this was a substantial building of some importance.

The parallel lines of resistivity data were combined and processed using RES3DINV - a threedimensional inverse modelling program. The data were then sliced in order to provide a plan view of this feature at different depths (Figure 7). At shallow depths, down to about $40 \mathrm{~cm}$, no clear pattern can be discerned, although there is evidence of some high resistivity blocks. However, the parallel walls of the building are clearly defined between 40 and $86 \mathrm{~cm}$. The presence of the walls can still be discerned at a greater depth, but their presence cannot be determined below about $2 \mathrm{~m}$.

\section{Ground-penetrating radar characteristics of zone 1}

A GPR section taken across zone 1 is shown in Figure 8 and is representative of all the radar lines. It shows two hyperbolic responses at depth

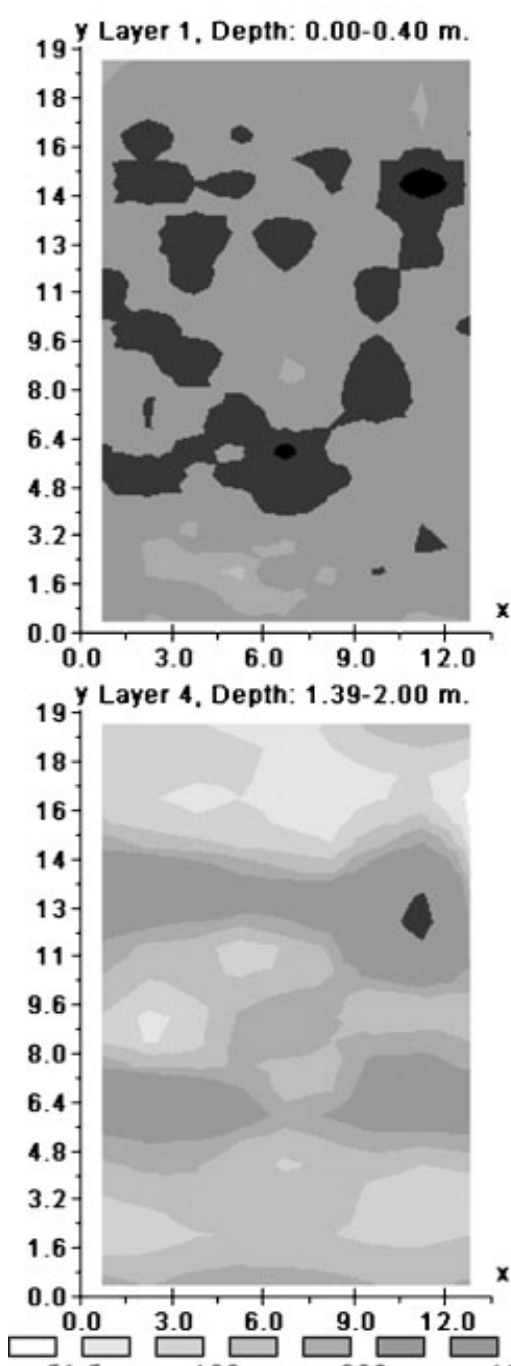

$51.5 \quad 103 \quad 208$
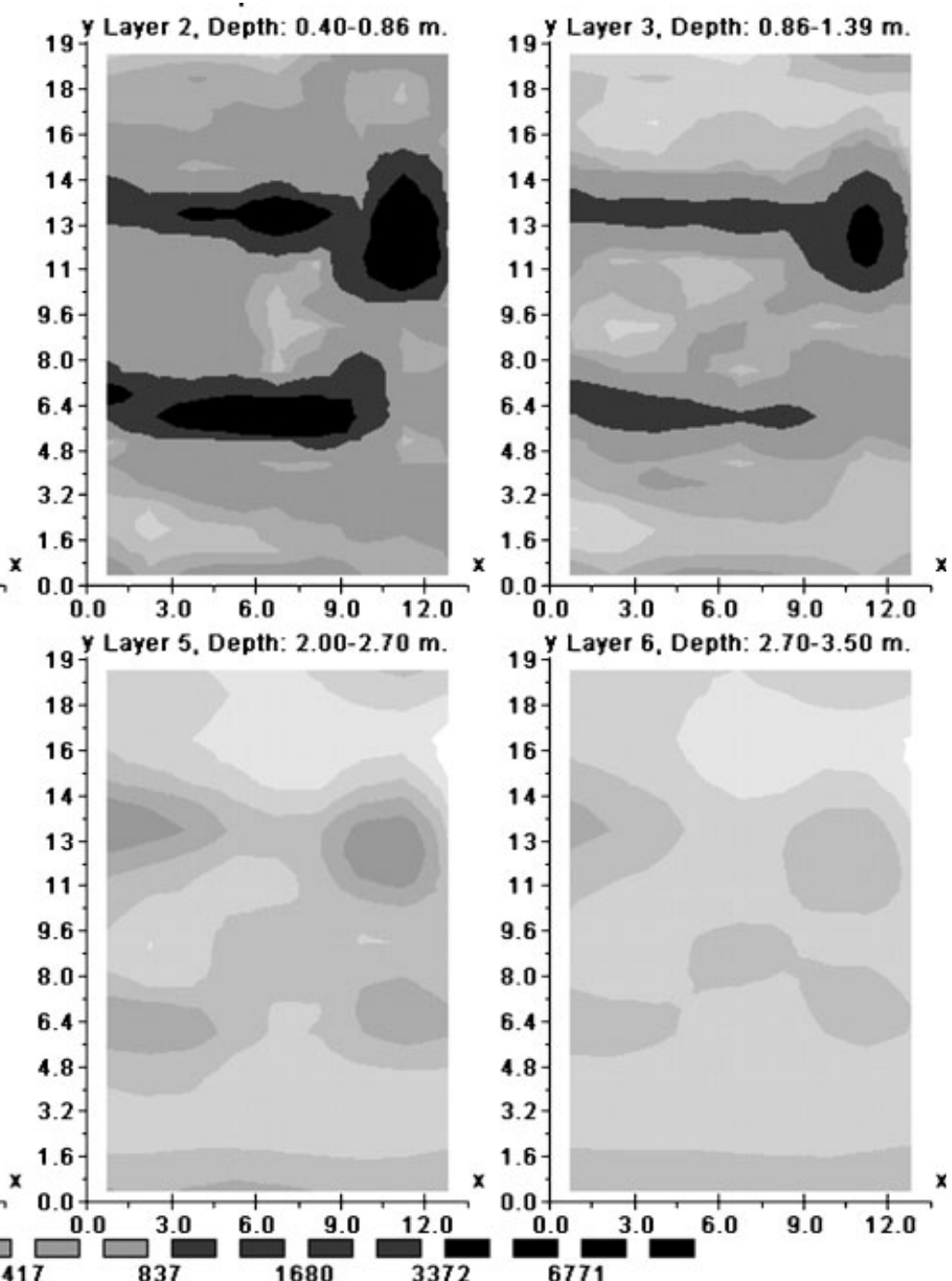

837

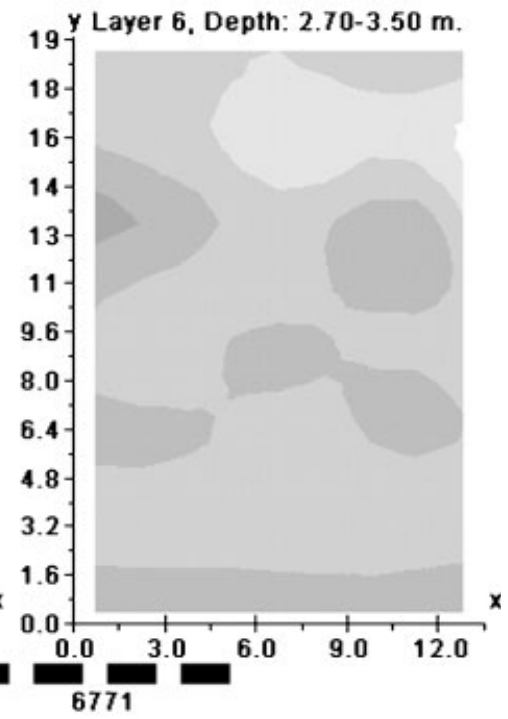

X Unit Electrode Spacing 1.5M. Y Unit Electrode Spacing 0.8M. Iteration 6 - RMS Error 4.78\%

Figure 7. Areal plot of resistivity for zone 1 at different depths. See Figure 5 for location of plots. 


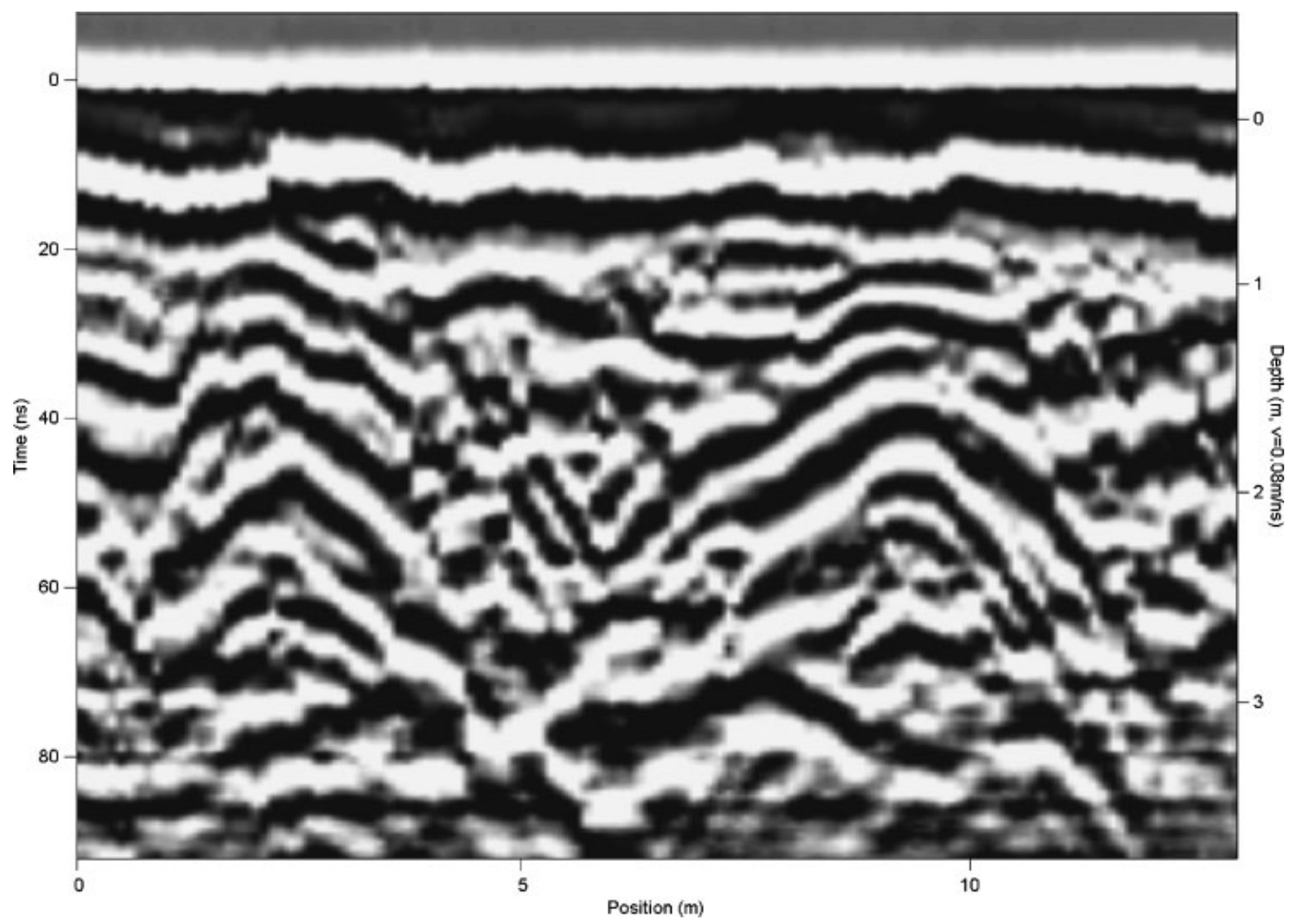

Figure 8. Ground-penetrating radar section across zone 1, south to the left.

due to the walls. They are located the same distance apart as the walls discovered by resistance and resistivity methods and confirm the existence of these features. The 21 closely spaced parallel lines of data collected were collated using the EkkoMapper program, depth slices were obtained for each GPR dataset and the data gridded to produce a sequence of twodimensional plots showing the spatial variation in amplitude response for different depths. Figure 9 shows the results of depth slices for a $13 \mathrm{~m}(\mathrm{~N}-\mathrm{S})$ by $10 \mathrm{~m}(\mathrm{E}-\mathrm{W})$ area. The thickness interval for each depth slice is $40 \mathrm{~cm}$. As with the resistivity data, no distinctive patterns were obtained near the surface (Figure 9a). However, the presence of the walls is clearly delineated in the $0.8-1.6 \mathrm{~m}$ depth range as two linear pale bands extending across the image (Figures $9 \mathrm{~b}$ and 9c). The signature for the walls is much reduced in the 1.6-2 $\mathrm{m}$ range (Figure $9 \mathrm{~d}$ ) and is absent at depths greater than $2 \mathrm{~m}$.
Approximately $5 \mathrm{~m}$ south of this building (location 3, Figure 5b) an excavation in the 1970s located nine skeletons (eight adults and one child) buried together at a depth of only about $15 \mathrm{~cm}$ (Sweetman, 1978). The skeletons post-date the late thirteenth century and appear to have been buried hurriedly presumably in a location which was considered 'religious' ground. Their close proximity to the building in zone $1(5 \mathrm{~m})$ and their alignment parallel to the walls of the building support the hypothesis that it had a religious significance and was a building associated with Clonard monastery.

\section{Conclusions}

The geophysical investigations undertaken in this project have uncovered many anomalies which may be related to the monastic settlement 

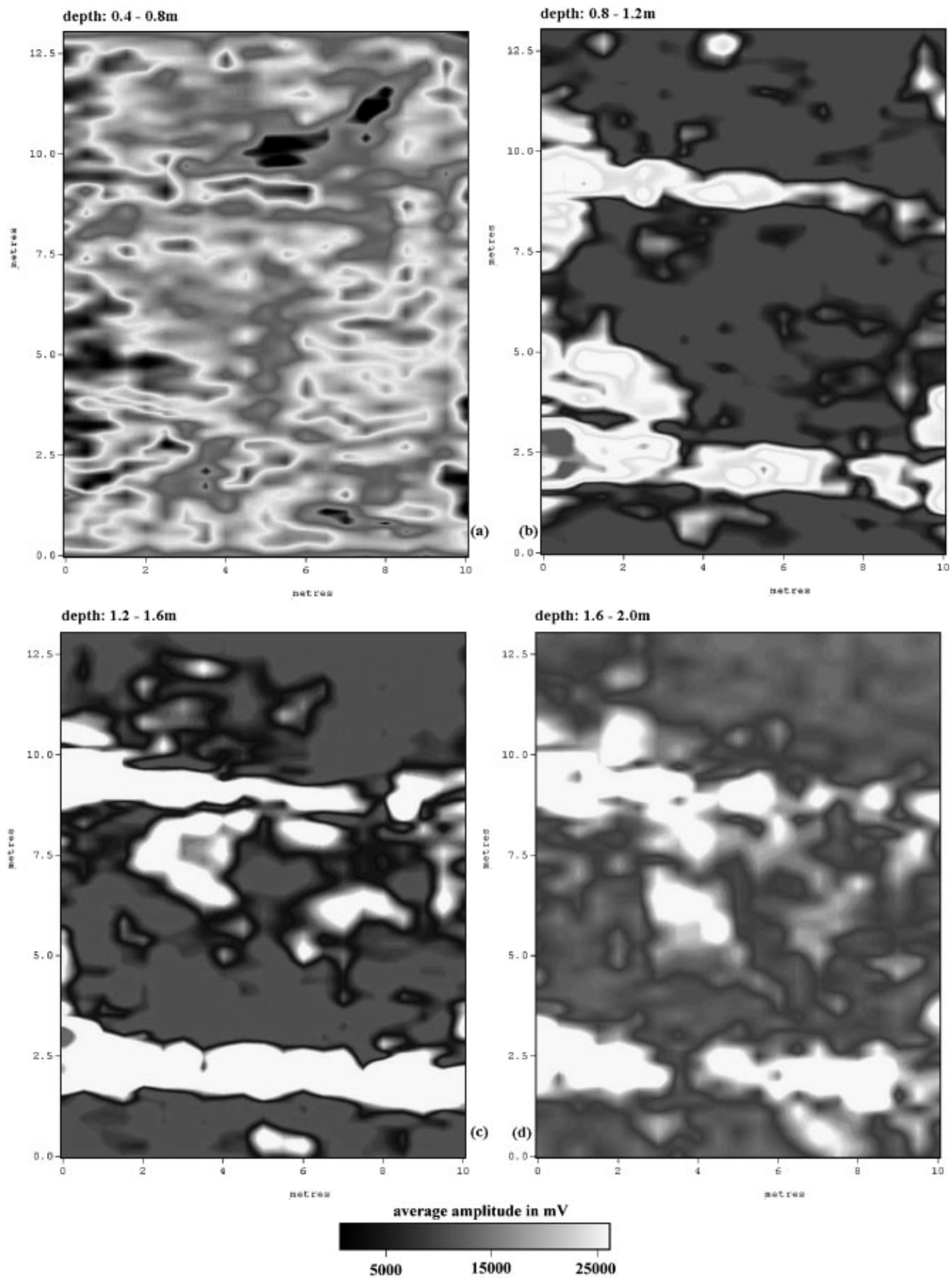

Figure 9. Areal plot of ground-penetrating radar data for zone 1 at different depths. See Figure 5 for location of plots. 
at Clonard. Most of the features east of the supposed site of the abbey (area A) are indicative of field boundaries. However, a much greater diversity of geophysical signatures are located south and west of the proposed abbey site (area B). A $60 \mathrm{~m}$ subsquare enclosure is adjacent to a $300 \mathrm{~m}$ long palaeochannel. There are three areas in which anomalous magnetic readings are recorded which might indicate sites of human activity. In addition, four zones show large concentrations of high resistance readings suggesting that buildings were located in these areas. One of these (zone 1) has resistivity and groundpenetrating radar characteristics which indicate the presence of an E-W aligned building approximately $7 \mathrm{~m}$ wide (N-S direction) and about $15 \mathrm{~m}$ long $(\mathrm{E}-\mathrm{W})$.

The combined application of various geophysical techniques has maximized the amount of information acquired in the study area or strengthened the resultant interpretation. Some of the features located in area A are associated with both magnetic and resistance anomalies. Magnetic gradiometry alone would not have detected the east-west aligned building and other zones in which it is postulated that other buildings are present. The palaeochannel yields a clearly defined coherent magnetic signature whereas its resistance signature is not as pronounced and it does not appear to be a single feature on the resistance plot. The correlation of similar patterns in both the ground penetrating radar and resistivity plots over the east-west aligned building in zone 1 both support the interpretation that the anomalies represent major walls.

\section{Acknowledgements}

The authors would like to thank Lorraine O'Reilly for helping in the collection of data and The Heritage Council, the Royal Irish Academy and the Bishop of Meath for financial assistance.

\section{References}

Archdall M. 1786. Monasticon Hibernicum. L. White: Dublin.

Cogan A. 1874. The Ecclesiastical History of the Diocese of Meath Ancient and Modern, Vol. I. WB. Kelly: Dublin.

Conyers L, Goodman D. 1997. Ground-penetrating Radar: an Introduction for Archaeologists. Altamira Press: Walnut Creek, California.

D'Arcy MR. 1974. The Saints of Ireland. Irish American Cultural Institute: St Paul, Minnesota.

Flanagan L. 1990. A Chronicle of Irish saints. Blackstaff Press: Ireland.

Gaffney C, Gater J. 2003. Revealing the Buried Past. Tempus: Stroud.

Gibson PJ, George DM. 2004. Environmental Applications of Geophysical Surveying Techniques. Nova Science: New York.

Hickey E. 1998. Clonard: the Story of an Early Irish Monastery 520-1202. Hickey: Leixlip, Ireland.

Loke MH. 2001. 2-D and 3-D Electrical Imaging Surveys. http://www.geoelectrical.com/.

Loke MH, Barker RD. 1995. Least-squares deconvolution of apparent resistivity pseudosections. Geophysics 60: 1682-1690.

Loke MH, Barker RD. 1996. Rapid least squares inversion of apparent resistivity pseudosections by a quasi-Newton method. Geophysical Prospecting 44: 131-152.

Sensors \& Software Inc. 1996. PulseEKKO RUN User's Guide v. 1.2. Technical Manual 25. Sensors \& Software Inc: Mississauga, Ontario.

Similox-Tohon D, Vanneste K, Sintubin M, Muchez P, Waelkens M. 2004. Two-dimensional resistivity imaging: a tool in archaeoseismology. An example from ancient Sagalassos (southwest Turkey). Archaeological Prospection 11: 1-18.

Sweetman PD. 1978. Excavation of medieval 'field boundaries' at Clonard, County Meath. Journal of Royal Society of Antiquaries of Ireland 105: 10-21. 